\title{
Globalizing curriculum beyond the classroom: Service Learning Programs benefit Students, impact local issues and answer local needs to build bridges between cultures
}

\author{
Philippe Briot $^{1}$, Ludivine Ponson ${ }^{2}$, Thierry Leterre ${ }^{3}$ \\ ${ }^{1}$ John E. Dolibois European Center, Miami University, USA-Luxembourg, ${ }^{2}$ Department of \\ Linguistic Science, Université Bordeaux-Montaigne, France, ${ }^{3}$ John E. Dolibois European \\ Center, Miami University, USA-Luxembourg
}

\begin{abstract}
Based on a case study, this article analyzes the effects of introducing Service Learning in the curriculum of a study abroad US Center. Explaining institutional motivations as well as resistances, this research shows that this introduction was essentially academic in nature, and represented an innovative way to some perceived deficiencies in the acquisition of learning objectives by students. This research also indicates the specific conditions in which this type of Service Learning can thrive, such as a strong welfare state context, which is both a support and a potential issue, and the necessity to have students supervised in their service by local managers. More general lessons are drawn for a successful practice of Service Learning abroad: clearly defined academic goals, strict distinction between Service Learning and other forms of volunteering or experiential learning, ethical rules to prevent patronizing attitudes among volunteers.
\end{abstract}

Keywords: Service Learning;curriculum; innovation. 


\section{Introduction}

This article analyzes how Service Learning (SL) contributes to the formal acquisition of learning objectives in the context of a sociology course delivered at a European Center. We will emphasize the necessity to envisage SL from a curricular standpoint, thus differentiating this type of community-based learning experience from co- or extra-curricular forms of engagement in the local community. Ultimately, we will show how SL can creatively transform and enhance the development of a curriculum abroad.

We will follow a case study methodology, regarding the European Center as a whole as an "integrated system" and the Sociology course in which SL takes place as a subsystem, or "working part" to use Yazan's terminology in his survey of case study methodology (Yazan, 2015). In this institutional approach, where the institution is recognized as a "structuring base" (Di Maggio \& Powell, 1997) we use the institutional memory as shared/lived by actors to provide structured comprehension of the case and we will use assessment questionnaires to consider the impact on learning process as an empirical basis for the analysis.

We will be presenting briefly the tenets of SL as understood in the US., before analyzing how they have been implemented in the case at hand, before reflecting on students' learning outcomes. We will not shy from pointing out some limitations in the approach, nonetheless underlining its overwhelming benefits.

\section{What are Service Learning and International Service Learning?}

SL is a feature of US. higher education which is relatively uncommon in the European landscape of universities. It is "a course-based, credit-bearing educational experience in which students (a) participate in an organized service activity that meets identified community needs and (b) reflect on the service activity in such a way as to gain further understanding of course content, a broader appreciation of the discipline, and an enhanced sense of civic responsibility.” (Bringle \& Hatcher, 1995).

Quite unanimously, the idea of making students actors of their own learning is attributed to John Dewey (Eyler \& Giles, 1994; Pacho, 2015). The idea was reinforced in the 1980s, with David Kolb, who developed his "Experiential Model Learning" (Kolb, 1984) based on Dewey's work. Such considerations meshed with first attempts of direct learning in the U.S. from the beginning of the $20^{\text {th }}$ century (mostly on an agricultural basis and during the Great Depression), and the impact of Civil Rights movements while civic organizations such as Peace Corps and VISTA emerged. (Flecky \& Gitlow, 2011). Hence a political tone to SL that is still present nowadays (Mitchell, 2007) despite growing concerns that "rhetoric may be winning over reality” (Butin, 2006). 
International Service Learning (ISL), or Global Service Learning (GSL), is the implementation of SL in the context of a study abroad program, i.e. outside of the home country of the institution to which the students participating in the course belong: "ISL (...) can be conceptualized as the intersection of three different educational domains: (a) service learning, (b) study abroad, and (c) international education.”(Bringle, Hatcher, \& Jones, 2010)

\section{The case: from resistance to involvement of stakeholders}

The case we study is the one of a long-established (over 50 years) European Center from Miami University, a public Midwestern university. This European Center abroad is the only permanent location of this university outside of the US. even if the university offers many study abroad opportunities to its students, consistently ranking among the top 5 US public universities as regards to study abroad. The teaching language is English and students are not required to be proficient in any of the local languages (Luxembourg has 3 official languages). Academic regulations and accreditation rules are the one of the US. home campus.

The home university in the US. is known for its long tradition of service, having been named to the [US] President's Higher Education Community Service Honor Roll from 2007-2015, and winning in 2012 the Presidential Award.

Consistent with this tradition and general know-how, the university's Center abroad is characterized by large offerings in the field of "out-of-class” learning activities spanning from study tours and field trips, to independents studies, many of them in the context of service to the local community, volunteering, and internships. SL, implemented in 2014, is the latest addition to this already large range of offerings.

The development of SL corresponded to the preoccupation of stakeholders who felt that current students were not really or sufficiently immersed in the community and stayed in their "bubble" (a term often used at the time). Those stakeholders were: a/ the advising Committee in the US. b/ alumns of the program and c/ local (Luxembourgish) alumns.

For the leadership of the European Center abroad, this general preoccupation had more narrow educational and academic. The lack of integration of students weakened their ability to reach the Learning Objective of the Center to "develop and exercise the ability to communicate and act respectfully across linguistic and cultural differences”. SL was perceived as a way to bring rigor in the experience of students by enhancing their reflection as regards to their context thanks to the academic part of SL. This analysis was not unanimously shared, and some significant resistance had to be overcome, before SL was tied to a sociology course, “Aspects of European cultures” which carries 4 credits (3 in-class, 1 SL). Evolving from a short 7-week program in 2014, SL is now part of the regular semester offerings. 


\section{SL Learning Objectives and Service}

The Learning Objectives of the sociology course are delineated in three main rubriques: 1/ Welfare state ("take an in-depth look at the nature and practice of social welfare institutions in a wealthy country, and the challenges faced due to rapid urban population growth and economic development") 2/ Equity ("critically engage students in asking questions of "why".) 3/ Education ("understand how a country manages to integrate a massive foreign population and give equal opportunities”).

The service part of the course consists in a weekly community service for a minimum amount of 20 hours - usually more. Community-based service activities are combined with in-class learning activities and student reflection: students provide service in their community that is directly connected to their academic coursework and the community provides an educational experience for the student.

\section{A specific program: learning/teaching French with refugees}

One program has to be set apart as a radical innovation which has, to our knowledge, no equivalent: it is the opportunity offered to American students to co-teach French to migrants learners through a communicative approach method. This makes the experience unique in the sense that students teach a language they are themselves learning, which disrupts the dominant paradigm of "teacher as authority”(Portes \& Smagorinsky, 2010). In the situation of students teaching refugees, which they do under the supervision of a qualified French teacher, they also learn from others, as they develop linguistic skills and interact over the material taught. Beyond enhancing their practice of French, students learn from students/migrants' experience.

A first iteration of this program also included the development of a nursery for the children of the refugees coming to campus for their lessons. The nursery was organized by students, some of whom specializing in early childhood education.

\section{Ethics of ISL}

Theoretically, ISL/GSL should follow the same guidelines as SL. It particular, it must abide by the strict connection between learning objectives in a class and service activities outside of the classroom. However, a quick survey of many programs labelled as "International Service Learning” abroad reveals significantly different scopes. ISL for instance advertises "Travel and volunteering" and Global vision puts forward its "25,000 travelers" for their "Service Learning" programs. Traveling and volunteering are emphasized rather than a specific credit-carrying, fully embedded experience. 
In reaction to this loosened approach of SL, a few principles were laid to keep the academic rigor of the program.

1/ SL strictly complies with its academic and curricular definition: offerings are clearly distinguished between what is and what is not SL. Volunteering opportunities, internships are also available to students, but the crucial difference is the embedment of service activities in a formal course approved by the authorities of the university in the US.

2/ SL is separated from "travel” experiences. Even though travels are considered and advertised as a desirable part of the experience of students abroad, they are recognized as different. The "travel" experience is meant to give an appreciation for differences and situations which will stay foreign to the travelers. Quite the opposite the goal of SL is to embed students in their local community, by developing personal links with it.

This difference does not necessarily entail a hierarchy. Both the development of a sense of belonging in the community through service and discovery in an outsider's position through travels are favored by the program. They are nonetheless kept separate as different goals to reach differently the Learning Objectives of the program in general.

3/ SL's organization avoids patronizing attitudes: While most volunteers have a genuine interest in helping others, their service can at the same time be seen as condescending or patronizing and akin to a "missionary attitude" (Weah, Simmons, \& Hall, 2000). This dimension is unconsciously embedded in the advertising material of many providers of ISL/GSL: brochures feature students usually white teaching or playing with people who are mostly Asian or African, often shown in their traditional outfit. It is an interesting display of striking cultural differences, but also a disturbing illustration of an exotic conception of the others, which is somewhat disheartening after decades of critical postcolonial studies.

SL in the case at hand avoids this potential slip into patronizing attitudes for structural and organizational reasons. In terms of organization, the academic supervisor is the SL coordinator of the university's Center abroad, but a local supervisor assigns tasks to the students. Students are thus embedded in the "chain of command" of the local structure. In terms of structures, students are volunteers in a Western European one of the highest GDP per capita country with a highly developed welfare state-superior in many regards to the US. situation.

As a side consideration, we can note that this situation constituted a challenge, and even a sort of "reversed challenge" for the SL coordinator: when state support is reasonably abundant, how can one entice partners in the community partners to collaborate with the university in terms of delivering content, guiding and managing students and act as teachers in the Service-Learning process? 
It is not necessary here to delineate the detail of the incentives which engage community partners in a SL project. Let us simply note they range from organizational requirements of developing operating ties with external organizations to the most and simplest humane curiosity for foreign youth. Beyond incentives, the arch-reason for having volunteers is that "there is no human community that is without needs or problems.”(McLeod, 2017) and therefore that there is always a demand for the original types of support that volunteers can provide. Even in a wealthy nation with a well-developed and funded welfare state, there are people left behind by poverty, urbanization, and a lack of proper education. This was aptly summarized by a student participating in SL: "I thought Luxembourg was a very rich country and it was jarring to know how many people need help”.

\section{Student impact}

Each semester students fill a questionnaire as part of their formal assessment. The analysis of the questionnaires shows that the objective of better integrating students in the community is met. "My service learning gave me the most realistic view of European life in Luxembourg. Deeper appreciation for the culture here was developed." "This project made me realize that there are many people in the Luxembourg community that care about the well-being of other people." "I have gotten to understand more about the culture of Luxembourg, as well as make connections with many students." "I was able to interact with other Luxembourgish students and adults from very different cultures than my own”. The experience of SL as a formal learning experience is also well understood: "I learned a lot about the welfare system in Luxembourg and how many people are affected by poverty in the community”. This formalization is sometimes tied to a specific academic input: "I am a psychology major [and] this was a really cool program to be able to see and learn from”. This does not preclude broader life lessons, which are the outcome of any volunteering experience: "this experience has taught me to keep an open mind when addressing how to deal with a dilemma”; "This service especially taught me about parenthood and how crazy kids can be. They can be a real annoyance but in the end are so fun.” A sense of reciprocity is also noticeable in the contributions: "I was able to learn things from all individuals I worked with and they were also able to learn things from me”.

When we read the answers to the questionnaires, some limitation can be found. Through their service, it appears that students gain a good grasp of the educational system in Luxembourg, its difference from the US., its specificities (especially in terms of multilingualism). They also understand issues of poverty and need. In other words, they cover correctly two of the three learning objectives. However, they are weaker in dealing with the third one, pertaining to the "why"? Why such differences? What are the limits of inclusion? Why this and not that organization? 
There are different ways to analyze such a limitation. One actually should make room for the fact that students are effectively trained to be respectful of their host country. They also enjoy their experience as volunteers, and even gain a higher appreciation for their host country due to their service. Such positive conditions make it difficult to adopt a more critical attitude towards their experience.

\section{Conclusion}

SL has reinforced the curriculum of a program abroad by providing innovative ways to reach its core objectives: make the students more familiar with their host country, separate their interests as travelers and as temporary immigrants (an aspect often skipped in the literature about study abroad) while embedding their sociology class in concrete social engagement. It has been the incentive for radical curricular innovation with the refugee language classes. Even more essentially, it has contributed to foster a reflection about the role played by a study abroad in the community as well as about the role played by this very community for this study abroad program. This is why, ultimately, we are talking about Service Learning and not about Global or International Service Learning. It corresponds to the elimination of a "missionary" understanding of service "from the outside". It also coheres with the conviction that educating the global citizen is giving her or him the responsibility to become a committed local citizen abroad.

\section{References}

Bringle, R. G., \& Hatcher, J. A. (1995). A Service-Learning Curriculum for Faculty. Retrieved from https://scholarworks.iupui.edu/handle/1805/4591

Bringle, R. G., Hatcher, J. A., \& Jones, S. G. (Eds.). (2010). International Service Learning: Conceptual Frameworks and Research (Iupui Series on Service Learning Research edition). Sterling, Va: Stylus Publishing.

Butin, D. W. (Dan W. (2006). The Limits of Service-Learning in Higher Education. The Review of Higher Education, 29(4), 473-498. https://doi.org/10.1353/rhe.2006.0025

Di Maggio, P., \& Powell, W. (1997). Le néo-institutionnalisme dans l'analyse des organisations. Politix. Revue des sciences sociales du politique, 10(40), 113-154. https://doi.org/10.3406/polix.1997.1703

Eyler, J., \& Giles, D. E. (1994). The Theoretical Roots of Service-Learning in John Dewey: Toward a Theory of Service-Learning. Michigan Journal of Community Service Learning, 1(1), 77-85.

Flecky, K., \& Gitlow, L. (Eds.). (2011). Service-learning in occupational therapy education: philosophy and practice. Sudbury, Mass: Jones and Bartlett Publishers.

Kolb, D. (1984). Experiential Learning: Experience As The Source Of Learning And Development (Vol. 1). 
McLeod, A. K. (2017). Service Learning and Community Engagement for English Classes. English Teaching Forum, 55(3), 20-27.

Mitchell, T. D. (2007). Critical Service-Learning as Social Justice Education: A Case Study of the Citizen Scholars Program. Equity \& Excellence in Education, 40(2), 101-112. https://doi.org/10.1080/10665680701228797

Pacho, T. O. (2015). Unpacking John Dewey’s Connection to Service-Learning. Journal of Education, 2(3), 9.

Portes, P., \& Smagorinsky, P. (2010). Static Structures, Changing Demographics: Educating Teachers for Shifting Populations in Stable Schools. English Education, 42(3), 236-247.

Weah, W., Simmons, V. C., \& Hall, M. (2000). Service-Learning and Multicultural/Multiethnic Perspectives: From Diversity to Equity. Diverstiy, Paper 3, 673-675.

Yazan, B. (2015). Three Approaches to Case Study Methods in Education: Yin, Merriam, and Stake. The Qualitative Report, 20(2), 134-152. 